\title{
On the Paradox of Identification of Point of Sales Data in Shopper Marketing
}

\author{
Hiroshi Koga
}

\begin{abstract}
Shopper marketing is the new marketing practice that influences the moment of purchase (Zero Moment of Truth). The essence of shopper marketing is that grasp an individual consumer behavior using identifying device, such as ID-POS and RFID. However, the author considers that shopper marketing is development of a product marketing technique unlike customer relationship marketing (e.g. one to one marketing). That is, shopper marketing is paradoxical. It is a reason why the directivity of shopper marketing is oriented product-centric rather than the individual, although using the purchase history data of the individual. Therefore, the purpose of this paper is to clarify the mechanisms that paradox of personal identification takes place. Therefore, this paper is organizing as follow. That is, first, the concept of shopper marketing is overviewed. Second, the focus of shopper marketing is revealed. Here, key words are diachronic and synchronicity. Then, by noting the difference personal purchase history data (diachronic) and collective characteristics data (synchronicity), mechanism that such a paradox occurs is clear. Finally, the possibility of paradox is pointed out.
\end{abstract}

Index Terms-Shopper marketing, personal information, purchase history data.

\section{INTRODUCTION}

Recent years, the shopper marketing has attracted attention over the years. Although shopper marketing is a relatively new concept and young substantive area, it is rapidly attracting attention from many researchers and practitioners. And, according to many researchers, the effect of shopper marketing is enormous [1], [2]. In addition, shopper marketing is also expected from practitioners.

For example, Gallagher has been quoted saying Rob Holston who is Deloitte's shopper marketing practice leader [3]. "Companies who are embracing shopper marketing and executing against a core set of principles are growing 50\% faster in the categories in which they participate."

In traditional marketing, it was important to improve the visibility and exposure of articles in store. However, in the shopper marketing, it is focused on proposition the meaning of the place of shopping that is based on the needs and psychology of shoppers [1]-[5]. For this reason, it is important to grasp the historical data of shopper behavior. In other words, the impelling force of shopper marketing is data, specifically, the personal attributes of shoppers, purchase history data of each shopper and causal data [2]. Therefore, information technology, such as ID-POS (Identification Point of Sales), RFID (Radio Frequency Identification), and

Manuscript received December 13, 2013; revised January 21, 2014.

Hiroshi Koga is with the faculty of Informatics, Kansai University, Takatsuki-city, Japan (e-mail: koga@ res.kutc.kansai-u.ac.jp). special cameras to record the movement of the eye has become a weapon [1], [2], [6], [7].

And, the introduction of shopper marketing should be careful enough to treat such a data in that these data are closely related to privacy. Many of the previous studies only emphasize the benefits of shopper marketing, but there is few to mention it to the dark side (that is privacy problem). This is the reason why take up the issue of privacy in the Shoppes marketing in this paper.

Thus, the purpose of this paper is to discuss privacy issues in shoppers marketing in the retail industries, such as GMS and grocery stores. Therefore, the research question of this paper is as follows. That is, could the shopper marketing using a personal identification device cause to violation of the right to privacy?

Then, the author's answer is "no." It is because shopper marketing has a focus in the product instead of an individual. In other words, the author would consider that shopper marketing is development of a product-centric marketing technique unlike customer relationship marketing (e.g. one to one marketing). This is paradoxical. Therefore, the author would like to clarify below the mechanism which paradox produces.

Thus, this paper is organized as follows. First, the underlying concepts of shopper marketing are overviewed. Second, the paradox of shopper marketing (that is, directivity of shopper marketing is oriented product-centric rather than the individual, although using the purchase history data of the individual.). Third, the mechanism which paradox occurs is clarified. Here, key words are diachronic and synchronicity. In particular, by focusing on differences between individual chronological (sequential) history data and the collective synchronic phenomenon, the difference in the approach of data analysis is shown. Thus, the paradox of shopper marketing is concluded. Finally, the possibility of paradox is pointed out. This discussion is followed by an outline of possible future scenarios in shopper marketing. The paper concludes with directions for further research in shopper marketing innovations.

\section{Theoretical BACKGRound: THE CONCEPT OF SHOPPER MARKETING}

In this section, the author would review the underlying concepts of shopper marketing. First, the definition of marketing is checked. Now, shopper marketing is defined in broader terms as "the planning and execution of all marketing activities that influence a shopper along, and beyond, the entire path-to-purchase, from the point at which the motivation to shop first emerges through to purchase, 
consumption, repurchase, and recommendation" [1]. A more narrow definition is conducted by Deloitte Developments as "all marketing stimuli, developed based on a deep understanding of shopper behavior, designed to build brand equity, engage the shop-per (i.e., a consumer in 'shopping mode'), and lead him/her to make a purchase" [5].

There is a common point in these definitions. The key feature of shopper marketing is approach to improve the management of store operations from the shopper's point of view [1]-[7]. The conversion of such a viewpoint often has been pointed out as a difference from traditional marketing Table I. Submit your manuscript electronically for review.

TABLE I: KEY DIFFERENCES BETWEEN TRADITIONAL MARKETING AND SHOPPER MARKETING

\begin{tabular}{|c|c|c|}
\hline Dimension & Traditional Marketing & Shopper Marketing \\
\hline Principal & $\begin{array}{l}\text { Use pull and push } \\
\text { strategy }\end{array}$ & $\begin{array}{l}\text { Influence trigger in shopping } \\
\text { cycle }\end{array}$ \\
\hline $\begin{array}{l}\text { Domination } \\
\text { focus }\end{array}$ & Brand of goods & $\begin{array}{l}\text { Action and cognition of } \\
\text { shopper }\end{array}$ \\
\hline $\begin{array}{l}\text { Primary } \\
\text { target }\end{array}$ & $\begin{array}{c}\text { Consumer } \\
\text { ( Second Moment of } \\
\text { Truth ) }\end{array}$ & $\begin{array}{c}\text { Shopper } \\
\text { ( First Moment of Truth ) }\end{array}$ \\
\hline $\begin{array}{l}\text { Mode of the } \\
\text { individual }\end{array}$ & Consumption & Shopping \\
\hline $\begin{array}{l}\text { Category } \\
\text { focus }\end{array}$ & Single category & Multiple category \\
\hline Promotion & $\begin{array}{l}\text { Relate to attitudes of } \\
\text { goods }\end{array}$ & $\begin{array}{l}\text { Relate to shopping situation } \\
\text { ( contexts ) }\end{array}$ \\
\hline
\end{tabular}

Source: the author revised based on [1].

As shown in Table I, shopper marketing and traditional marketing are very different in various dimensions of marketing. In this case, it is possible to extract common keywords behind the differences in each dimension. Such a common keywords are threefold: First is focus on the field of shopping at in-store: Second is focus on the shopper: Third, information technology to record the behavior of shoppers has be-come a driving force (See Fig. 1).

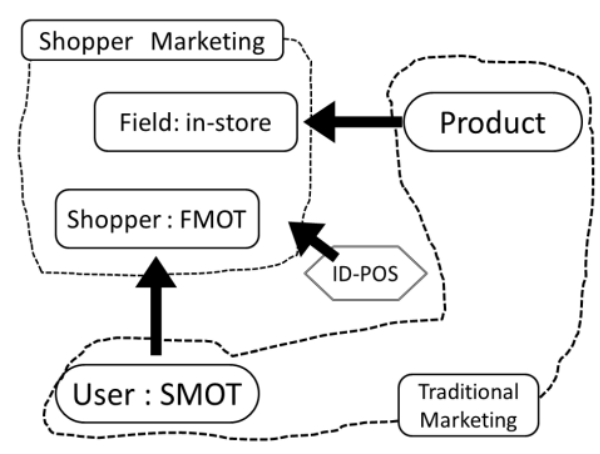

Fig. 1. Three features of shopper marketing.

The first is that it focuses on not end user of goods (articles or products) but shopper. In other words, the focus of shopper marketing is "FMOT: the first moment of truth" [8]. The moment of truth refers to the moment when the consumer facing product. And FMOT means that the moment that shoppers encounter articles in stores. According to a survey of P \& G, FMOT is only 3-7 seconds [2], [7]. It is time taken to decision whether he buys the item after a shopper looks at the displayed it first. Furthermore, the moment of actually using goods is called "SMOT: the second moment of truth." And, even if the same customer, it is selectively used the name, "shopper" in the timing of FMOT, and "consumer" in the timing of the SMOT. By this distinction, the understanding of consumer would be better and deepen.

\section{Focus on Shopping}

The first is that it has an interest in the field of shopping. Rather than product attributes, attention to the cognition and action of shoppers in-store. Traditional strategic marketing has been focused on the appeal of the product attributes. Then, perception the product that is a bundle of value is the first step of marketing and is the goal. As a compass for that, tools such as $4 \mathrm{P}$ have been developed. However, rather than product attributes, shopper marketing will focus on setting the stage of shopping.

Take advantage of the ID-POS. As mentioned above, Shopper marketing differs from traditional marketing. Table 1 captures some of these key differences. Support the new dimension of shopper marketing is a new information technology, such as IDPOS, IFID, and so on. That is, it is a technology of individual recognition.

\section{MAnAgerial Challenges of ShOPPER MARKeting}

In this section, the author would discuss the key issues and managerial challenges related to shopper marketing. Now, shopper marketing is expected as a powerful tool to overcome the obstruction of the retail situation. Not only so, but it is expected that marketing realizes the relation of triple win (shopper-retailer-manufacturer) [1].

However, shopper marketing is not a silver bullet ${ }^{1}$. First, it is necessary to point out the problem of the reliability of the data acquired from such as ID-POS.

Here, if you compare the airline and the retail industry, the difficulty of obtaining personal information of each shopper is well understood. The airline industry was a pioneer in the use of purchasing data. For example, it is said that such as Frequent Shopper program that provides a variety of benefits in accordance with the boarding distance has arose from the airline industry.

Unlike the airline industry which is obligated to create a passenger list, there is no necessity that a shopper calls themselves a name of their own on retail trade. Thus, there are people who want to avoid the disclosure of personal information, because they do not feel the necessity for providing personal information to shop. In fact, in the retail industry, there is no choice but to use the data that shoppers were self-reported. For this reason, it is not a few cases the cardholder's age is more than 100 years old [9]. That people do not want to give out personal information is the reason why the self-reported data is incorrect. In other words, many people would have regarded as the privacy of their own purchase history data. Unlike boarding record, there is no need to associate willingly purchase history and personal information.

In this context, the expansion of the concept of privacy has been deeply involved. At the beginning, the right of privacy would be considered as a right to be let alone. However, if

\footnotetext{
${ }^{1}$ Since it is the arms which can defeat an immortal monster "werewolf" with one blow, the bullet which melted and cast the silver cross is used in the sense of the tool which can solve a difficult problem at a stretch.
} 
after a period, the idea of right to control one's personal information has been born.

Reflecting these trends, the customer (I used this term without distinction the two aspects of the customer and shopper) was to raise the awareness of privacy. As a result, various approaches to conceptualize information privacy have been proposed in the literature across. More than 15 years ago, it has been argued that the privacy concern is divided into four components (for example, collection of personal information, unauthorized secondary use of personal information, errors in personal information, and improper access to personal information) [10].

However, the collection of accurate information has become possible because the penetration of the Internet, privacy consciousness of mankind has been changed. For example, people have come to be considered privacy concern as collection of personal information, control over personal information, and awareness of organizational privacy practices [11].

Furthermore, these days, typology of the approach of privacy research has advocated: privacy as a human right, privacy as a commodity, privacy as a state of limited access, and privacy as the ability to control information about oneself [12].

In this way, the growing awareness that want to control the information of themselves has led to lack of member information to support ID-POS. Thus, shoppers would not want to disclose information about themselves (please remember the differences between the aviation industry). The privacy concerns are not limited to the more well-known cases of junk mailing [13].

Above all, shoppers would not provide information about the household, such as family structure, age, sex, and so on. For example, I will assume that beer sold. In this case, it is difficult for it to grasp the object for oneself or a spouse. Of course, since shopper marketing is focused a shopper (FMOT) instead of a user (SMOT), it can be said that it is good. However, it is useless, if the essential information of shopper's attribution is mistaken or it is missing. The reason why retailer would energetic to issue of a member card with a credit function and/or an electronic money function and/or to recommendation of the member registration by a mobile phone is in exact grasp of shopper information.

The right to control one's personal information causes another trap. Idea of possible control is understood as property information. Considering personal information as the property is contrary to the original concept of the right to privacy. First of all, privacy is because property rights were advocated as a right to differ. As a result, those who want to return to provide personal information appeared. In other words, privacy or personal information would become a discount voucher. As a result, the right which is not property came to be treated as property. It is a paradoxical phenomenon [14]. Here, those who seeking compensation for providing personal information are price sensitive. Therefore, in the field of Customer Relationship Management, such a layer of customer is considered less attractive. But, I would like to discuss at another opportunity about this point [14].

Above, I have discussed personal information, such as your name and address and age. Here, such information is not expected to change dramatically over time. So, it can be said to be static privacy information. Or such information can be said to be the reference information registered before utilizing ID-POS. However, in shopper marketing, there is action history information acquired through devices of identification, such as ID-POS.

And, since it becomes possible to extract privacy information from a shoppers' purchase history data, the problem of marketing and privacy is becoming inescapable.

About this point, the example of a Target corporation which is a major supermarket company in U.S. is famous. It is the episode that Target knew about the pregnancy of one schoolgirl before parents know [15]. Direct mail has arrived on one high school girls. Then, her father was surprised after opening the letter. Because it was the goods guide for pregnant women. Father was angry and made a phone call of com-plaint. According to the description of the corporation, direct mail had been shipped in that her purchase history is similar to pregnant women. Although the company apologize, in fact, it is true that his high school daughter was pregnancy. Father had been told the truth from his daughter later. Father was embarrassing twice.

In this way, historical data may act closely related to personal privacy. And, when information is used in another context which the owner of information does not in-tent and/or image, invasion of privacy is felt in many cases. Therefore, an opinion like triple Win is considered to be too optimistic.

Even ad-dresses the issue of privacy and data reliability, further, it is necessary to overcome the biggest obstacle in order to perform the shopper marketing. "Power of inertia" inhabits changing the focus of activity. Or only the introduction of individual recognition technology, shopper marketing is not fully functional. Thus, organized effort is essential. Therefore, the key is "organizational practice" and/or "performativity",

Taking advantage of the data that has been acquired through ID-POS (and/or any devices) is not only data analysis. Practice should be required based on an analysis result. The result of data analysis is only a hypothesis. It should be necessary to prove whether a hypothesis is truth. It is exactly organizational practice. And, results of practice are verified by data. Thus, it is important to turn the cycle of a hypothesis and verification. Therefore, the organizational challenge of shopper marketing is the data analysis through practice.

\section{PARADOX OF SHOPPER MARKETING}

In this section, I propose a point of view for shopper marketing and privacy in the retailing environment. The

\footnotetext{
${ }^{2}$ The terms "performativity" denotes the capacity to execute an action, to carry something out actually and thoroughly, as well as to do according to prescribed ritual (Berns2012). If the description is vulgar, even if only to hear the voice of the movie, we can distinguish between police and criminals. Wording is different because I am. If the position changes, it also changes wording. By the way, by mimicking the wording of gay or juvenile delinquent, gradually, there might become similar to them. Wording is to socially constructed positions. Thus, the concept of performativity can be considered as follow: it is the nature that practice through the action will produce further action that commitment to emerge gradually through practice process behavior, even in perfunctory practice.
} 
research question of this paper is shown again here. That is, could shopper marketing avoid a privacy problem? The author's answer is "yes." The reason is as follows.

At first, by comparing it with customer relationship management (CRM), I would clarify clues to consider the privacy problem in shopper marketing.

CRM Directs Diachronic Contexts. By the way, it is difficult to find out a widely approved definition of CRM. However, I would like to adopt as "a combination of business process and technology that seeks to understand a company's customers from the perspective of who they are, what they do, and what they are like" [16]. In particular, CRM is emphasis on focused on the individual.

Then, the features of CRM are fourfold: first, to identify the profitable individual customer at the beginning; Second, to accumulate and store individual purchase history in chronological order; Third, to analyzed personal tendencies and values; Fourth, to make organizational effort as to maximize the lifetime value (LTV) of individual customers ${ }^{3}$.

Thus, the first step of CRM is customer segmentation and profiling from the purchase history data accumulated. Using statistical analysis like RFM, customers would be divided an individual $^{4}$. And, LTV of individuals was calculated. These procedures are based on the individual's purchase history. Such a view is based on analysis ac-cording to a time-axis [16], [17]. In other words, it is a time series (or sequential) analysis of purchase behavior. I called the purchase characteristic that such analysis approach clarifies as "diachronic contexts" [18].

Therefore, diachronic contexts would be closely related to privacy issues in that it assumes personal verification.

Shopper Marketing Directs Synchronic Contexts. On the other hand, the focus of shopper marketing is not individual customer but in-store advertising, promotion and design initiatives [5]. As described above, shopper marketing would focus on FMOT and the field of shopping. Therefore, scientific analysis the effect on shopper behavior of change in sales floor is essence of shopper marketing. For example, change of POP (point of purchase), zoning, facings, and a method of displaying articles are considered.

Then, the features of shopper marketing are also fourfold: first, to grasp the cur-rent state of the sales floor: Second, to carry out in-store advertising, promotion and design of in-store; Third, to measure changes in shoppers' behavior in order to investigate the effect of in-store operation; Fourth, to reexamine the current state of the store in order to find a further problem.

Thus, the first step of shopper marketing is changing the viewpoint (from article and customer to in-store and shopper) And, information technology is used to grasp the current state and to measure effect. For example, new devices such as special glasses for recording the gaze of shoppers and RFID are used to grasp the status quo. Then, ID-POS is used both

${ }^{3} \mathrm{LTV}$ is one of the indicators to measure the value of the customer, and calculated as the amount of money a customer purchase of the company. See [17].

${ }^{4}$ RFM is a method used for analyzing customer behavior and defining market segments. RFM stands for Recency: How recently did the customer purchase? , Frequency: How often do they purchase? , Monetary: How much do they spend? See [17]. grasping and measuring. Therefore, ID-POS is considered to play central role in shopper marketing. However, ID-POS is used to grasp the change in the behavior of shoppers. Therefore, in shopper marketing, focus is placed on changes in buying behavior patterns over a period of time, instead of individual customer's purchase history. In other words, the essence of shopper marketing is not the time series analysis of the individual purchase history, but reaction of shopper to in-store operation, i.e. a collective commonality (synchronic changes) of reaction.

In this paper, such a feature is called "synchronic contexts or synchronicity" as contrasted with "diachronic contexts" [18]. For example, one customer buys toothbrush, s/he may buy toothpaste next time. In this case, it would be meaning that analyzing serial relations in purchase history. Next, please imagine that one shopper buys a chocolate. Probably, we could not know such as chocolate for diet, for the reward oneself, or for her/his children. In this case, the background information of the individual product purchase would be important. I call such background information the synchronic context in this paper.

First of all, shopper marketing observes the collective synchronic phenomenon (synchronic contexts), instead of an individual time series (diachronic contexts). And, the synchronic context is background information of the product use, regardless of a personal attribute. In other word, it is information to be created by interpreting "the first moment of truth." Therefore, shoppers' purchase history data is not used for identifying an individual, but is used in order to extract a collective inclination. Thus, the feature of diachronic contexts is integral and cumulative analysis. On the other hand, the feature of synchronic contexts is differential and collective analysis.

By the way, practicing shopper marketing, introducing ID-POS to identify the change of shopper behaviors is essential. However, in CRM (diachronic contexts), POS is a tool for distinguishing the individual of the customer (See Table II).

TABLE II: TwO CONTEXTS OF DATA ANALYSIS

\begin{tabular}{l|l}
\hline \multicolumn{1}{c|}{ Diachronic Contexts } & Synchronic Contexts \\
\hline Cumulative & Collective \\
Integral & Differentiation \\
Time Series & Before and After an Experiment \\
Chronological & Hypothesis and Verification \\
Sieve & Net for capture \\
To extract a target & To discover a common pattern \\
\hline
\end{tabular}

Then, although ID-POS would be strengthened the individual recognition function of POS, it is used to grasp the shoppers' response to change of in-store operation. Therefore, ID-POS is not used to the accumulation and utilization of purchase history. Rather, despite the use of ID-POS to identify the individual, the individual abstracts. There is a paradoxical phenomenon that the author called "a paradox of ID-POS."

As a result, shopper marketing would reduce the potential for invasion of privacy. Such a view differs from CRM (in particular, the conventional database and/or one to one marketing). Therefore, shopper marketing would have the mechanism of concealment of privacy. It is the main contribution of this paper that point out this idea. 
If we stand on the point of view of synchronic contexts, it is necessary to transform the concept of customer loyalty.

First of all, customer loyalty is divided into two types. It is loyalty of products and loyalty of store. Then, diachronic approach focuses on the loyalty of products. And, there was a tendency to treat as a synonym for the concept of the two. On the other hand, synchronic approach focuses on behavioral changes of shoppers only. Then, loyalty of shop is considered as the result of behavioral changes of shoppers. In addition, the loyalty of products could not be measured in that it has been considered that shopper might be different from customer.

Let me think again an example of the above-mentioned chocolate. Why does s/he want to buy chocolate? S/he buys it for her/his children, for nutritional support, for coffee break, and so on. To find the meaning of such, it is a subject of shopper marketing.

Even in the same article, meaning of it will vary depending on how display. For example, usually, chocolates and snacks displayed according to raw material. Then, shopper marketing is to induce shopping mode by changing the exhibition method of articles. In other words, shopping marketing is to give a new meaning to articles. Therefore, not only scientific data analysis but an interpretation (hypothetical setup) becomes important. Then, it is important to investigate not a loyalty but a meaning.

\section{CONCLUSION}

In Japan, shopper marketing is just beginning. To that end, there are not many commentators point out the dark side of shopping marketing (i.e. privacy issue). However, in the near future, due to the expansion of the concept of privacy (from "a right to be let alone" to a right to control one's personal information" and "a right to be forgotten"), there would be a growing awareness of privacy for customer identification (and the usage of its devices: ID-POS and membership card). Therefore it seems that it is important to argue about a privacy issue of shopper marketing.

Therefore, in this paper, the meaning of shopper marketing was examined and different logic from CRM has been clarified. Then, the author considers that shopping marketing approach has the potential to circumvent privacy issues. In this regard, the author would discuss. In addition, this paper is only intended to suggest a point of view for shopper marketing. Empirical study of the effectiveness of the model is a challenge for the future.

\section{ACKNOWLEDGMENT}

A part of this research was supported by the Ministry of Education, Culture, Sports, Science and Technology as a Support Project for Strategic Collaboration between Private Universities (2009-2013).

\section{REFERENCES}

[1] V. Shankar, J. J. Inman, M. Mantrala, E. Kelley, and R. Rizley, "Innovations in shopper marketing: current insights and future research issues," Journal of Retailing, vol. 87, supplement 1, pp. 29-42, 2011.

[2] M. Stahlberg and V. Maila (eds.) Shopper Marketing: How to Increase Purchase Decisions at the Point of Sale, Second Edition, Kogan Page Ltd., 2012.

[3] J. Gallagher. (2008). Shopper Marketing Programs Fall Short: Study. [Online]. Available: http://m.supermarketnews.com/marketing/shopper-marketing-program s-fall-short-study

[4] G. Pincott. (2007). Putting the Shopper Back into Marketing. [Online]. Available:

http://www.wamda.com/web/uploads/resources/MillwardBrown_Poin tOfPurchase_Dec07.pdf

[5] Deloitte/Grocery Manufacturers Association. (2007). Shopper Marketing: Capturing a Shopper's Mind, Heart and Wallet. [Online]. Available:

http://www.deloitte.com/dtt/cda/doc/content/us_cpg_ShopperMarketi ngStudy_2007opt.pdf

[6] H. Sorensen, Inside the Mind of the Shopper: The Science of Retailing, Pearson Prentice Hall, 2009.

[7] T. Yada, T. Washio, and H. Koga, "A framework of shopping path research: new frontier in marketing research," The Japanese Society for Artificial Intelligence, SIG-KIS, Japanese, vol. 91, pp. 1-6, 2010.

[8] E. Nelson and S. Ellison, "Shelf promotion: in a shift, marketers beef up ad spending inside stores," The Wall Street Journal, September 21, A1, 2005.

[9] S. Suzuki. (2014). ID-POS changes MD of GMS and the role of real low-class distilled spirits. SHOCHU NEWS. Japanese. [Online]. Available: http://www.syochu-tok.com/news/news-suzukism

[10] H. J. Smith, J. S. Milberg, and J. S. Burke, "Information Privacy: Measuring Individuals' Concerns about Organizational Practices," MIS Quarterly, vol. 20, no. 2, pp. 167-196, 1996.

[11] N. K. Malhotra, S. S. Kim, and J. Agarwal, "Internet users' information privacy concerns (IUIPC): The construct, the Scale, and a causal model," Information Systems Research, vol. 15, no. 4, pp. 336-355, 2004.

[12] H. J. Smith, T. Dinev, and H. Xu, "Information privacy research: an interdisciplinary review,” MIS Quarterly, vol. 35, no. 4, pp. 989-1015, 2011.

[13] J. C. Sipior and B. T. Ward, "The ethical and legal quandary of email privacy," Communications of ACM, vol. 38, no. 12, pp. 48-54, 1995.

[14] H. Koga, "Problems in the use of personal information from the point of view of relationship marketing," ETHICOMP2013 Proceedings, pp. 282-287, 2013.

[15] C. Duhigg. (2012). How Companies Learn Your Secrets. New York Times Magazine. [Online]. Available: http://www.nytimes.com/2012/02/19/magazine/shopping-habits.html? pagewanted=all\&_r=1

[16] J. Kim, E. Suh, and H. Hwang "A model for evaluating the effectiveness of CRM using the balanced scorecard," Journal of Interactive Marketing, vol. 17, no. 2, pp. 5-19, 2003.

[17] C. Robert, R. C. Blattberg, G. Getz, and J. S. Thomas, Customer Equity: Building and Managing Relationships as Valuable Assets, Harvard Business School Press, 2001.

[18] H. Koga, "On taxonomy of contextual marketing," International Proceedings of Economics Development and Research, vol. 59, pp. 141-145, 2013.

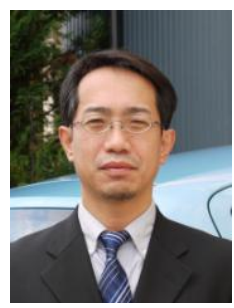

Hiroshi Koga is a professor of information management at the Faculty of Informatics and a researcher at the Data Mining Applied Research Center, Kansai University, Osaka, Japan. He studied multivariate analysis and theory of decision-making at the doctoral program in business administration, Kobe University of Commerce, Kobe, Japan. His current research interest is in the use of private data in marketing. 